\title{
Mapping proteolytic cancer cell-extracellular matrix interfaces
}

\author{
Katarina Wolf · Peter Friedl
}

Received: 2 April 2008/Accepted: 10 June 2008/Published online: 4 July 2008

(C) The Author(s) 2008

\begin{abstract}
For cancer progression and metastatic dissemination, cancer cells migrate and penetrate through extracellular tissues. Cancer invasion is frequently facilitated by proteolytic processing of components of the extracellular matrix (ECM). The cellular regions mediating proteolysis are diverse and depend upon the physical structure, composition, and dimensionality of the ECM contacted by the cell surface. Cancer cells migrating across 2D substrate contain proteolytic structures such as lamellipodia, invadopodia, and the trailing edge. Likewise, invasive mesenchymal migration through 3D fibrillar ECM, as monitored for HT1080 fibrosarcoma and MDAMB-231 breast carcinoma cells by submicron-resolved imaging, is mediated by several types of proteolytic structures rich in filamentous actin, B1 integrin, and MT1MMP with distinct location and function. These comprise (i) anterior pseudopod bifurcataions and the nucleus corresponding to zones of local cell compression by constraining collagen fibers, (ii) lateral small spikes that protrude into the ECM and cause small spot-like proteolytic foci, and (iii) a strongly proteolytic trailing edge sliding along reorganized ECM fibers. Through their
\end{abstract}

K. Wolf $(\bowtie) \cdot$ P. Friedl

Department of Cell Biology (283), Nijmegen Center for Molecular Life Science, Radboud University Nijmegen

Medical Centre, P.O. 9101, 6500 HB Nijmegen,

The Netherlands

e-mail: kata.wolf@gmx.de

P. Friedl

Rudolf Virchow Center, DFG Research Center for Experimental

Biomedicine, University of Würzburg, Würzburg, Germany

P. Friedl

Department of Dermatology, University of Würzburg,

Würzburg, Germany combined action these proteolytic surface structures cleave, remove, and realign ECM barriers, support rear end retraction, generate tube-like matrix defects and laterally widen existing tracks during 3D tissue invasion.

Keywords Cancer - Invasion - Migration - Proteases · Proteolysis · ECM - Lamellipod · Invadopod · Pseudopod . Lateral spike $\cdot$ Cell compression $\cdot$ Microtrack

$\begin{array}{ll}\text { Abbreviations } \\ \text { 2D } & \text { Two-dimensional } \\ \text { 3D } & \text { Three-dimensional } \\ \text { ECM } & \text { Extracellular matrix } \\ \text { FAK } & \text { Focal adhesion kinase } \\ \text { GFP } & \text { Green Fluorescent Protein } \\ \text { MMP } & \text { Matrix metalloproteinase } \\ \text { MT1-MMP } & \text { Membrane-type 1 MMP } \\ \text { PY } & \text { Phosphotyrosine } \\ \text { uPA } & \text { Urokinase plasminogen activator } \\ \text { uPA-R } & \text { Urokinase plasminogen activator receptor }\end{array}$

\section{Introduction}

The progression of cancer is a complex process that includes the migration-associated proteolytic interaction of cancer cells with extracellular matrix (ECM). Cell migration requires anterior protrusion, attachment, localized ECM degradation together with acto-myosin contraction and rear end detachment [1]. In vivo, invading cells are confronted with structurally distinct types and spatial dimensions of tissue structures, such as two-dimensional (2D) surfaces or three-dimensional (3D) ECM.

2D ECM substrata comprise (1) basement membranes representing dense sheets of laminin, type IV collagen and 
Fig. 1 Distinct proteolytic cell-ECM contact structures in different surroundings. (a) Cells migrating across 2D ECM degrade matrix underneath the cell body at lamellipodia and podosomes. While lamellipodia grow outward, ECM-binding receptors such as $\beta 1$ or $\beta 3$ integrins accumulate at cell-ECM contact zones. Proteases, such as MT1-MMP or MMP-2 localize near the lamellipodial edge and mediate ECM degradation. As a consequence of migration, cells leave a path of degraded ECM behind. (b) Cells on homogeneous 3D ECM can form proteolytic and non-protrusive podosomes or proteolytic and protrusive invadopodia, both containing F-actin, $B 1$ integrins and MT1-MMP together with actin-binding proteins. Podosomes exist as dot-like, ca. $1 \mu \mathrm{m}$ short and transient formations, lasting for several minutes, while invadopodia are $>2 \mu \mathrm{m}$ long and protrude into the matrix, possessing a life time of up to $1 \mathrm{~h}[23,26]$. Invadopodia are morphologically similar to small filopodia [57]. Differences to nonproteolytic filopodia, however, exist in the molecular assembly, such as colocalization of cortactin and phosphotyrosine (PY) and their protrusion perpendicular to the cell body $[8,13,26,57]$. (c) Cells migrating within 3D interstitial ECM extend anterior and lateral protrusions, such as pseudopodia and spikes that degrade ECM (top). Posterior to the initial attachment zone, cells cleave belt-like fiber compressions at the bifurcation of pseudopodia and across cell body and nucleus. Upon forward movement, partially degraded ECM fiber ends are opened and realigned along a 3D proteolytic microtrack (bottom). Arrows, direction of migration

other structural proteins located underneath epithelia or endothelia of the skin, inner cavities, such as at the peritoneum, ventricles of the brain, and blood or lymph vessels, or (2) ossified bone surfaces [2-4]. When cells migrate across such surfaces, ECM degradation occurs only underneath the cell body (Fig. 1a, b).

3D tissue structures in vivo display a heterogeneous network of fiber scaffolds of variable density, orientation, and mechanic strength. Connective tissues rich in fibrillar collagen I or III, elastic fibers and other ECM components are present in and around most organs, such as skin, breast or gut. Cancer cells need to penetrate such interstitial tissue before reaching vessels for hematogenic or lymphogenic dissemination [5-7]. While invading, tumor cells are surrounded by ECM that simultaneously acts as structural barrier. Therefore, proteolytic cell structures arise from all sides of the cell, interact with 3D ECM circumferentially, and support local disruption and restructuring of the tissue scaffold (Fig. 1c). In 3D invasion, proteolytic cell surface structures are homologous in subcellular position and molecular regulation to those formed in 2D models, albeit their precise topography and mode of ECM remodelling are different. As an example, actin-rich flat lamellipodia formed on 2D substrate correspond to cylindrical-shaped pseudopodia that extend along and protrude through fibrillar tissue in a 3D environment (Fig. 1) [8, 9].

Here we visualize and classify the subcellular location and function of proteolytic structures in migrating cancer cells. Known cellular regions degrading 2D surfaces will be compared to newly identified surface-localized structures executing 3D ECM breakdown. a

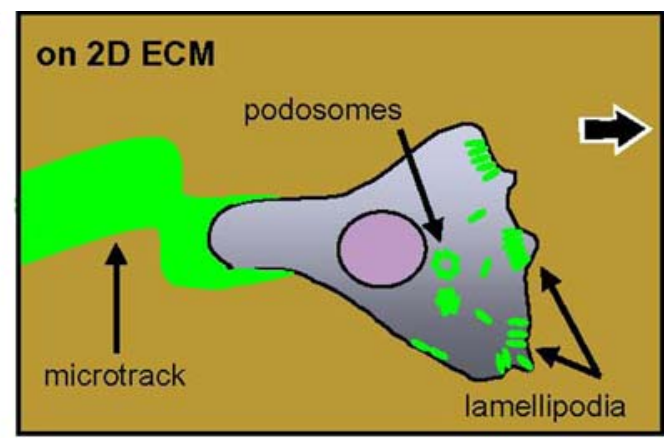

b

on 3D ECM

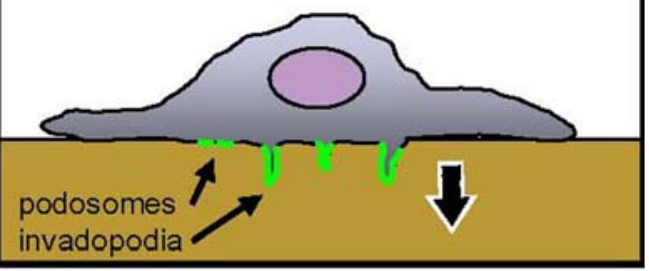

C

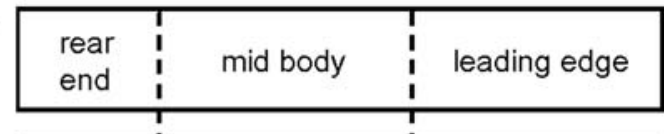

in 3D ECM: lytic cell protrusions

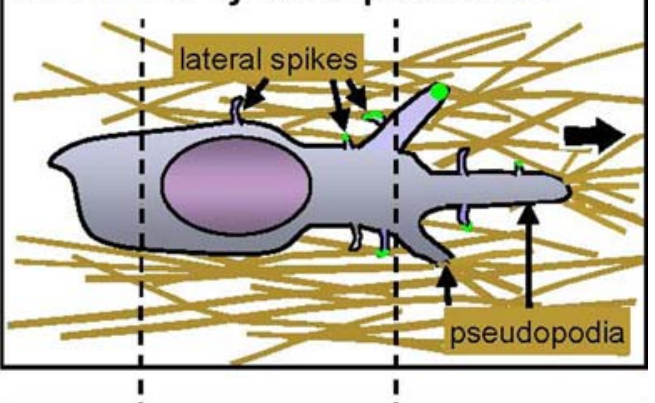

in 3D ECM: lytic ECM structures

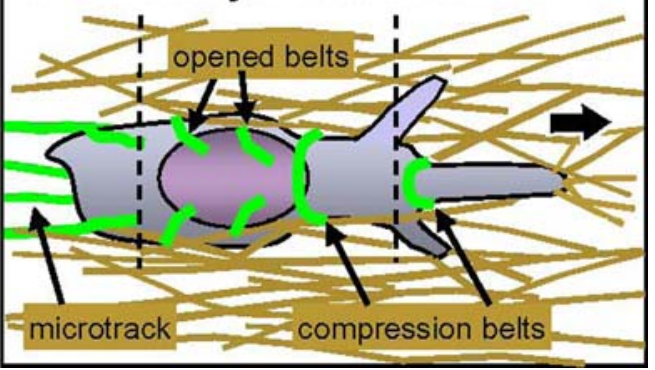

Experimental models for imaging protease function at the cell-ECM interface

1To characterize the location, structure and function of proteolytic cell-ECM interactions in diverse environments, 
Table 1 Experimental models for examining protease activity and ECM degradation in vitro and in vivo

\begin{tabular}{|c|c|c|c|}
\hline $\begin{array}{l}\text { Detection } \\
\text { principle }\end{array}$ & $2 \mathrm{D}$ & Transmigration assays & $3 \mathrm{D}$ \\
\hline Loss of substrate & $\begin{array}{l}\text { Thin layer of unpolymerized or } \\
\text { polymerized ECM coated onto 2D } \\
\text { carrier (Substrate: gelatin, collagen, } \\
\text { fibronectin, matrigel, dentin, apatite; } \\
\text { carrier: glas, plastic); detection of } \\
\text { degradation by using fluorescently } \\
\text { labelled ECM components }[28,37,60]\end{array}$ & $\begin{array}{l}\text { Transwell porous membranes coated } \\
\text { with ECM (matrigel, collagen, } \\
\text { fibronectin) at upper, lower, or both } \\
\text { sides }[3,20,61] \\
\text { Basal lamina-like membrane produced } \\
\text { by cells on collagen [3] }\end{array}$ & $\begin{array}{l}\text { In vitro reconstituted 3D ECM polymers } \\
\text { (gelatin, collagen, matrigel, fibrin, } \\
\text { functionalized hydrogels) } \\
{[7,9,35,50,62,63]}\end{array}$ \\
\hline Dequenching & $\begin{array}{l}\text { Layer of unpolymerized or polymerized } \\
\text { substrate (collagen, gelatin, casein, } \\
\text { matrigel) containing quenched } \\
\text { fluorophore } \\
{ }^{\mathrm{DQ}} \text { FITC-collagen I [59], } \\
{ }^{\mathrm{DQ}} \text { BODIPY-casein [64] }\end{array}$ & & $\begin{array}{l}\text { Polymerized 3D ECM (collagen I and } \\
\text { IV), containing quenched fluorophore } \\
{ }^{\mathrm{DQ}} \text { FITC-collagen I [9], } \\
{ }^{\mathrm{DQ}} \text { FITC-collagen IV [32] } \\
\text { Histological sections of frozen cancer } \\
\text { samples overlaid with quenched FITC- } \\
\text { containing gelatin (in situ zymography) } \\
\text { [65, 66] } \\
\text { Macroscopic live-imaging of proteolytic } \\
\text { regions in mice using i.v. injected } \\
\text { polyethyleneglycol (PEG) carrier with } \\
\text { proteolysis-susceptible peptide and } \\
\text { quenched fluorophores [11, 12] }\end{array}$ \\
\hline $\begin{array}{l}\text { Detection of } \\
\text { cleavage-site } \\
\text { specific } \\
\text { epitopes }\end{array}$ & & $\begin{array}{l}\text { Isolated decellularized basement } \\
\text { membrane from in vivo tissue [3] }\end{array}$ & $\begin{array}{l}\text { Collagen I degradation in polymerized 3D } \\
\text { collagen lattice stained with } \\
\text { degradataion epitope-specific COL2 } 23 / 4 \\
\mathrm{C}_{\text {short }} \mathrm{Ab}[7,9] \\
\text { Collagen I, II and IV degradation epitope } \\
\text { in histological sections stained with } \\
\mathrm{COL} 2^{3 / 4} \mathrm{C}_{\text {short }} \mathrm{Ab}[67,68] \text { or HUIV } 26 \\
\mathrm{Ab}[69]\end{array}$ \\
\hline
\end{tabular}

distinct in vitro, ex vivo, and in vivo models have been developed (Table 1). 2D models mimic cell interactions with ECM surfaces, such as basal membrane or bone, and allow to investigate proteolytic structures underneath the cell body towards specialized ECM. Cell transmigration studies are possible by combining a 2D ECM surface with an underlying filter pore. The 2D surface of a 3D ECM permits analysis of cell invasion along and ultimately across a basememt membrane into tissue. 3D models mimic cell invasion through fibrillar interstitial ECM. Thus, each model represents a valuble tool to address particular aspects of proteolytic tissue degradation in vivo. Moreover, certain complex components of the tumor microenvironment, such as blood and lymph vessels, inflammatory infiltrate and de-novo ECM deposits by reactive cells, are poorly recapitulated by in vitro models [10] and therefore depend upon in vivo models of proteolytic cell invasion. However, because of current limitations of sensitivity, resolution, and reliability to detect proteolytic cleavage in vivo [11, 12], all presently available knowledge on cell surface structures involved in pericellular proteolysis of the ECM scaffold, either static or in real-time, is based upon in vitro imaging (Table 1) [7, 9, 13].

\section{Proteolytic structures during migration on 2D surfaces}

In 2D ECM models, such as fibronectin, matrigel or gelatin, proteolytic structures comprise lamellipodia, formed at the leading edge of migrating cells, and focalized adhesion structures that promote migration (Fig. 1a). Lamellipodia are broad flat protrusions that extend in front of a cell migrating on planar substrate and can be rich in proteases such as MT1-MMP, MMP-2, uPA-R/uPA, or seprase [1419]. These proteases can colocalize within integrin- or paxillin-containing foci nearby the leading edge [20-22] that, however, are considered distinct from focal complexes and adhesions. At variable location underneath the cell body, other focal dot-like actin-, cortactin- and B1 integrinrich adhesions, termed podosomes [23], and thin protrusions perpendicular to the cell body, termed invadopodia [26], interact with ECM, such as bone or basement membrane. Both structures measure $0.1-1 \mu \mathrm{m}$ in diameter, contain proteases including MT1-MMP or seprase, and form proteolytic zones that rarely measure more than $1 \mu \mathrm{m}$ in diameter but are sufficient to extend thin cell protrusions of several micrometer in length into the underlying ECM [13, 
23-27] (Fig. 1b). Whereas podosomes mostly appear in non-cancer cells, such as monocytes, endothelial cells, and Src-transformed fibroblasts, invadopodia are preferentially found in transformed cells, i.e. breast cancer, adenocarcinoma, and melanoma cells [13, 23, 25]. In summary, these different proteolytic structures are distinct in morphology, location, and life-time but they share membrane dynamics, cell surface adhesion receptors focalized towards the substrate, an underlying submembraneous dynamic actin network with actin-associated structural and signalling proteins, as well as the presence of proteases (Table 2). Eventually, cell migration on 2D ECM leads to microtrack formation consisting of degraded and cleared ECM along the migration path $[20,28,29]$.

\section{Proteolytic structures during 3D tissue invasion}

Until recently the cell structures generating surface-associated proteolysis in 3D tissues were unknown. However, novel multimodal imaging technology, such as confocal fluorescence and reflection, multiphoton-excited fluorescence and second harmonic detection, or scanning electron microscopy, now permits the reconstruction of proteolytic cell-matrix interactions in time and space. When embedded within 3D ECM, such as fibrillar fibrin or collagen lattices, or when seeded onto a 3D dermis slice ex vivo, many cell types including fibroblasts and cancer cells polarize and start to migrate [7, 9, 22, 30-32]. Cell surface adhesion receptors such as integrins, and ECM-degrading proteases can focally interact with the substrate in different cellular locations that convey specific functions, including (i) the leading edge and protruding pseudopodia with anterior zones of ECM degradation, (ii) the mid region that glides along the substrate and cleaves lateral ECM structures, and (iii) the retracting trailing edge that weakens adhesion bonds and supports forward movement of the cell (Fig. 1c) [33]. As on 2D surfaces, proteolytic cellular zones in migration through $3 \mathrm{D}$ ECM contain filamentous actin, actin-associated adaptor proteins, and adhesion receptors in close proximity with surface proteases (components listed in Table 2).

Proteolytic structures at the leading edge

During cell migration through 3D fibrillar ECM, such as a collagen lattice, the leading edge develops one or several actin-rich pseudopodia that protrude along and bind matrix structure whereby surface proteases, such as MT1-MMP, become focalized to the site of substrate binding (Fig. 2a) [22]. Anterior pseudopodia develop traction upon collagen fibrils that undergo radiary realignment towards the cell (Fig. 2a, white arrowheads), thereby forming anterior traction zones (Figs. 1c, 2a, white arrowheads). Similar to 2D cell migration, in 3D ECM, surface proteases become focalized to cell-ECM interactions at the leading edge. Accordingly, at anterior pseudopodia within 3D collagen MT1-MMP forms short-lived clusters (Fig. 2a, asterisks). In addition, at bifurcations between pseudopodia several micrometer rearward of the leading edge, so-called branch points, MT1-MMP forms a long-lived cluster (Fig. 2a, circle) that colocalizes with crossing fibers (Fig. 2a, empty arrowhead). Associated with such long-lived protease clustering, branch points show high levels of focalized collagenolysis (Fig. 2b-d, empty arrowheads). Whereas the tip of the leading edge is devoid of proteolysis, the first belt-like region of cell compression shows a focal collagenolytic maximum (Fig. 2d), suggesting that fiber belts that perpendicularly cross or encircle the cell body cause compression leading to local degradation of the physical obstacle. Since MT1-MMP is known to promote fibroblast

Table 2 Molecular contents of proteolytic cell structures and associated cell track of migrating cells

\begin{tabular}{|c|c|c|c|c|c|c|c|c|}
\hline & \multicolumn{4}{|c|}{ Adhesion-associated } & \multicolumn{4}{|c|}{ Protolysis-associated } \\
\hline & Integrins & FAK & F-actin & Cortactin & MT1-MMP & MMP-2 & uPA/uPA-R & Seprase \\
\hline \multicolumn{9}{|c|}{ Cell front/mid body } \\
\hline Lamellipodia & + & - & + & + & + & + & + & + \\
\hline Podosome & + & + & + & + & + & & & \\
\hline Invadopod & + & - & + & + & + & & + & + \\
\hline Pseudopod & + & & + & & + & + & & \\
\hline $\begin{array}{l}\text { Compression } \\
\text { zone }\end{array}$ & + & & + & & + & & & \\
\hline Lateral spike & + & & + & & + & & & \\
\hline Rear end & + & & + & & + & + & - & \\
\hline Microtrack & + & & + & & + & + & & \\
\hline
\end{tabular}

Legend: "+" present; "-" excluded; "empty" unknown

Bold represents to major parts of the cell body 

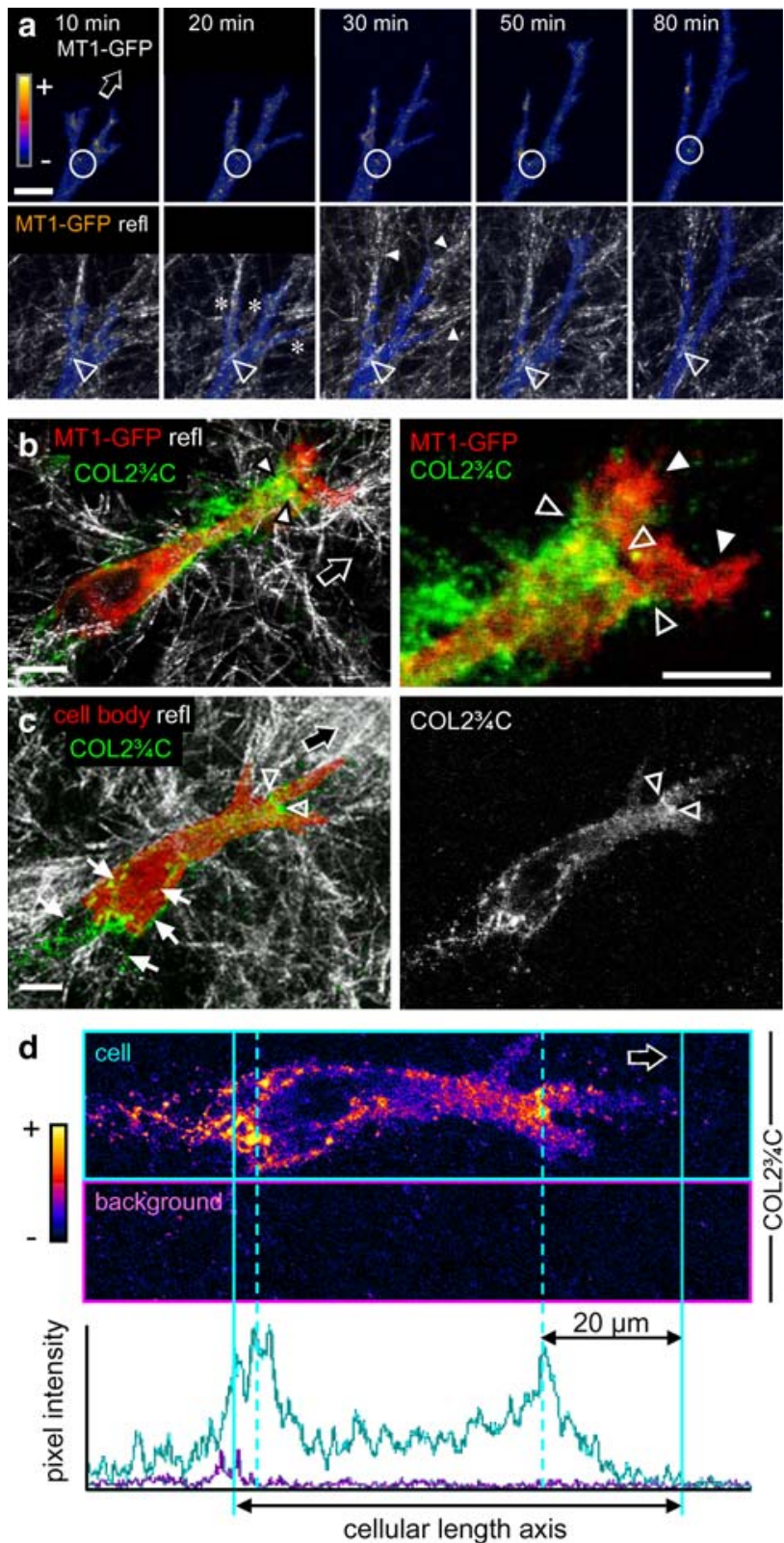

and cancer cell migration, one function of MT1-MMP is likely the removal of physical ECM constraints thereby facilitating cell gliding through newly formed tissue gaps [7, 9, 34-36]. Morphologically and functionally, 3D pseudopodia and 2D lamellipodia are related structures. Lamellipodia often generate proteolysis directly underneath the anterior rim or may form an anterior proteolysisfree region of several micrometer in length and an adjacent proteolytic zone [20,37], yet the spatio-temporal sequence between lamellipod protrusion and underlying ECM proteolysis is not known. Thus, in both 2D and 3D migration, the two-zone separation of the anterior leading edge could represent a general paradigm in proteolytic cell migration: while the front generates adhesion and traction towards the
4 Fig. 2 Spatio-temporal localization of proteases and proteolysis at the leading edge zone. Cells were detached by EDTA, polymerized into 3D collagen lattices (Vitrogen, Nutacon) and monitored by time-resolved $3 \mathrm{D}$ confocal fluorescence and reflection microscopy $\left(37^{\circ} \mathrm{C}\right)$, as described [9]. (a) Dynamic distribution of MT1-MMP-GFP (MT1GFP) in MDA-MB-231 breast cancer cell migrating within a 3D fibrillar collagen lattice. MT1-GFP accumulated over $80 \mathrm{~min}$ detection period or longer at bifurcation between two branching pseudopodia (open circles) and colocalized with adjacent collagen fibers (empty arrowheads). Fiber bundling (white arrowheads) at leading pseudopod tips (asterisk). Images display maximum intensity projections of z-stacks (6 $\mu \mathrm{m}$ in depth). (b) MT1-GFP in HT-1080 fibrosarcoma cell is localized at collagenolysis-free leading edge (white arrowheads, right) and further rearward at fiber contacts that contain collagen cleavage epitope (white arrowheads, left). The cell-collagen lattices in $(\mathbf{b}, \mathbf{c})$ were fixed with para-formaldehyde and stained for collagenolysis epitope (COL2 $3 / 4 \mathrm{C}_{\text {short }} \mathrm{Ab}$; IBEX, Canada) [58]. The onset of collagenolysis posterior to the leading edges is marked by empty arrowheads. (c) HT1080 cell overexpressing MT1-MMP (HT-1080/MT1) shows prominent collagenolysis at pseudopodal branches (empty arrowheads) and trailing edge. Parallel aligned proteolytic fibers at the rear zone (white arrows; as referred to later in the text). (d) Densitometric analysis of COL $23 / 4 \mathrm{C}_{\text {short }}$ signal (cell in cyan box, as in (c)), and comparison to background signal (purple box), depicted as mean pixels (total pixel brightness divided by pixel number). Peak intensities at ring-finger-like compression zone $20 \mu \mathrm{m}$ behind the leading pseudopod tip and at rear end. Yellow/ blue pixels correspond to bright/ weak signal (a,d). All bars, $10 \mu \mathrm{m}$. Black arrows, direction of migration

ECM substrate, the adjacent proteolytic zone mediates the cleavage of ECM structures simultaneous in time but distinct in location, without challenging anterior adhesion and traction force generation.

\section{Compression zones along the mid cell body}

Due to its membrane architecture, content and shape, the nucleus, although somewhat deformable, is considered as more voluminous and rigid structure than other regions of the cell $[38,39]$. In cancer cells moving through 3D fibrillar collagen, the cell diameter increases from the front and reaches its maximum at position of the nucleus (Fig. 3a) where crossing fibers generate stripe-like nuclear deformations suggestive of local pressure (Fig. 3a, white arrowheads). Consequently, collagen fibers circumferentially surrounding the cell body in a belt-like manner become degraded prior to and around the nucleus (Fig. 3a, b, empty arrowheads). The cleavage-sites colocalize with focalized F-actin (Fig. 3b right, arrowheads), MT1-MMP, and $B 1$ integrin [9], which is in structure and composition highly reministent of 3D matrix adhesions [40].

To explore the spatio-temporal fate of such processed fibers by live cells, a collagen lattice labelled with quenched FITC molecules was used for dynamic imaging of collagenolysis $[9,41]$. As the trailing edge moves forward (Fig. 3c, asterisk), a compression belt (empty arrowhead) becomes proteolytically opened which allows expansion of the cell diameter by $2 \mu \mathrm{m}$ (Fig. 3c, white arrowhead). Thus, at regions of cellular compression, collagen fibers 

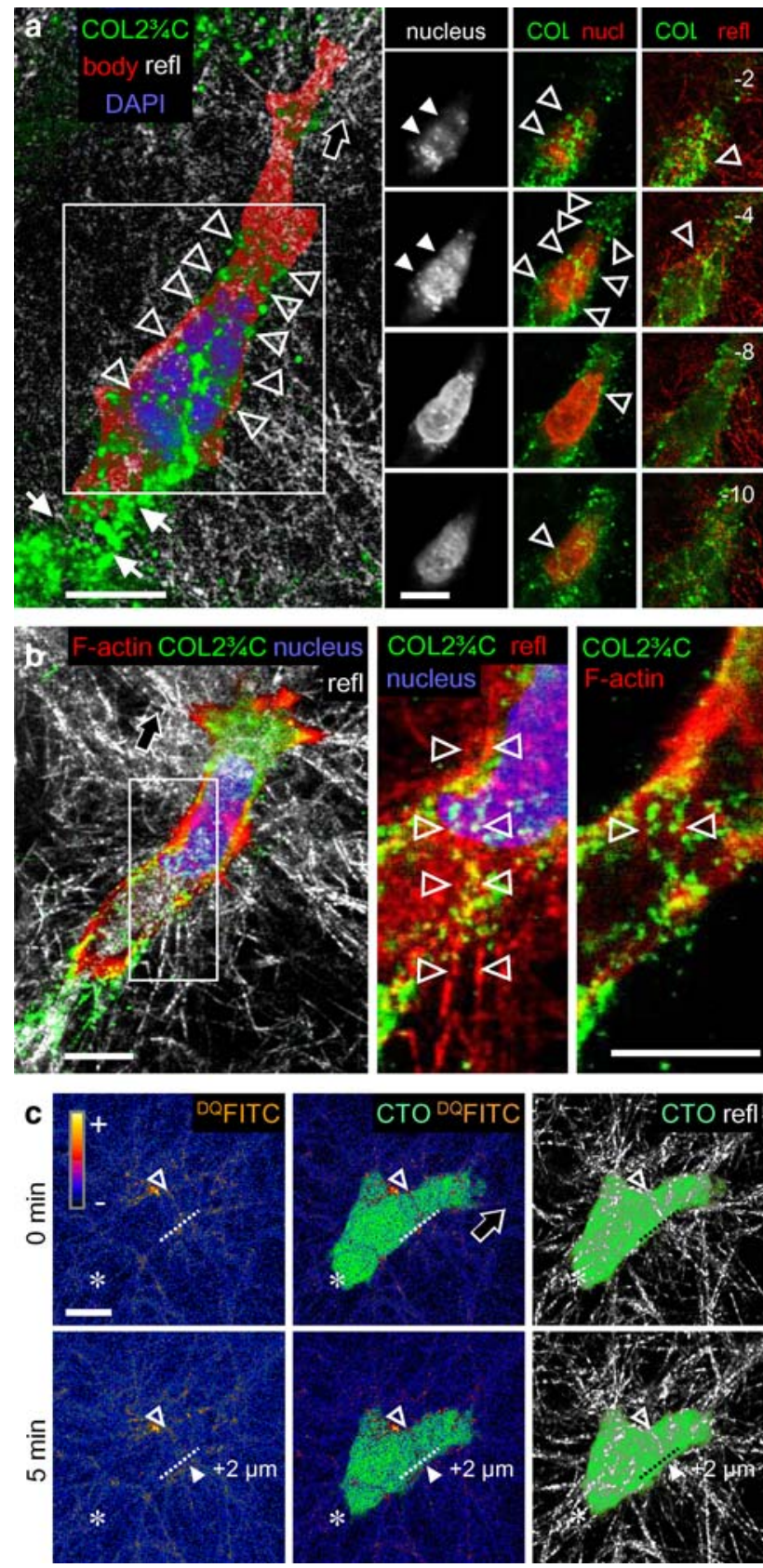

become sequentially degraded and opened to generate space for the migrating cell body and nucleus and are realigned in the direction of forward movement (Fig. 2c, white arrows) [9].

\section{Lateral spikes}

Similar to invadopodia forming underneath cells that spread on 2D substrate, cells moving through 3D collagen develop lateral actin-rich protrusions along the cell body which are short-lived (Fig. 4a) and display proteolytic
Fig. 3 Dynamics of fiber degradation at the HT-1080/MT1 midbody. (a) After migration in collagen lattice and fixation, samples were stained with $\mathrm{COL} 23 / 4 \mathrm{C}_{\text {short }} \mathrm{Ab}$ and DAPI. Multiple cleavage epitope-positive collagen fibers cross the cell body at different location including the nucleus (empty arrowheads). Perpendicular fibers cause belt-like imprints into the nucleus (white arrowheads), suggestive of local pressure. Partially degraded collagen fibers at the trailing edge (white arrows). Z-projection of whole cell (large image, left) and single $\mathrm{z}$-sections from indicated z-positions in $\mu \mathrm{m}$ (small images, right). (b) Fixed cell was stained with $\mathrm{COL} 23 / 4 \mathrm{C}_{\text {short }} \mathrm{Ab}$ and FITC-conjugated Phalloidin. Collagenolysis of two parallel collagen fibers crossing the mid cell body at the posterior part of the nucleus (arrowheads, middle) and colocalization with nucleated F-actin (b, right). (c) HT1080/MT1 cells were stained with Cell Tracker Orange (CTO), incorporated into collagen containing highly quenched FITC molecules $\left({ }^{\mathrm{DQ}} \mathrm{FITC}\right)$, and monitored by time-lapse confocal fluorescence and reflection microscopy at $37^{\circ} \mathrm{C}$ for $5 \mathrm{~min}$. Proteolytic prossessing of the crossing fiber (empty arrowheads, yellow pixels). Fiber cleavage was accompanied by a $2 \mu \mathrm{m}$ increase in cell diameter (dotted line, indicating lateral cell border before fiber cleavage; white arrowhead) and retraction of rear end (asterisk). (a-c) Images show projections of z-stacks of $6 \mu \mathrm{m}$ in depth. Yellow/blue pixels correspond to bright/weak signal (c). Bars, $10 \mu \mathrm{m}$. Black arrows, direction of migration

capability (Fig. 4b, c). These small protrusions, termed spikes [8], extent dynamically perpendicular to and interact with collagen (Fig. 4b, c, all arrowheads), and generate collagenolysis at a frequency of $30-50 \%$ (Fig. 4 b,c, white arrowheads). In contrast to the leading pseudopod, lateral spikes protrude and retract without direct signs of force generation, such as fiber alignment (Fig. 4c). Due to the presence of F- actin, B1 integrin, MT1-MMP and often focal collagenolysis (Figs. 4b, c), lateral protrusion likely execute additional proteolytic modification of the cellmatrix interface. Spikes are shorter than filopodia measuring up to $1 \mu \mathrm{m}$ in diameter and up to $10 \mu \mathrm{m}$ in length and showing a short life time in the range of minutes (Fig. 4a) [8, 42]. Taken together, lateral spikes correspond to invadopodia in molecular assembly, location, shape, and dynamics [23, 43, 44]. Future work will show whether lateral spikes also contain hallmarks of invadopodia, including cortactin and phosphotyrosine $[13,26]$.

\section{Trailing edge and microtrack formation}

For forward migration, cells resolve cell-matrix adhesions at the posterior cell edge which leads to gradual forward gliding of the rear end [1,33] (Fig. 5a, arrowheads). Several mechanisms are thought to synergize for focal contact disassembly and trailing-edge sliding, including inside-out signalling, proteolytic cleavage of focal contact components, the structural disintegration of the ECM substrate, and following adhesion ligand competition caused by diffusing ECM fragments [45-47]. In fibrosarcoma cells moving within fibrillar collagen, the collagenase MT1MMP degrading native collagen and the gelatinase MMP-2 

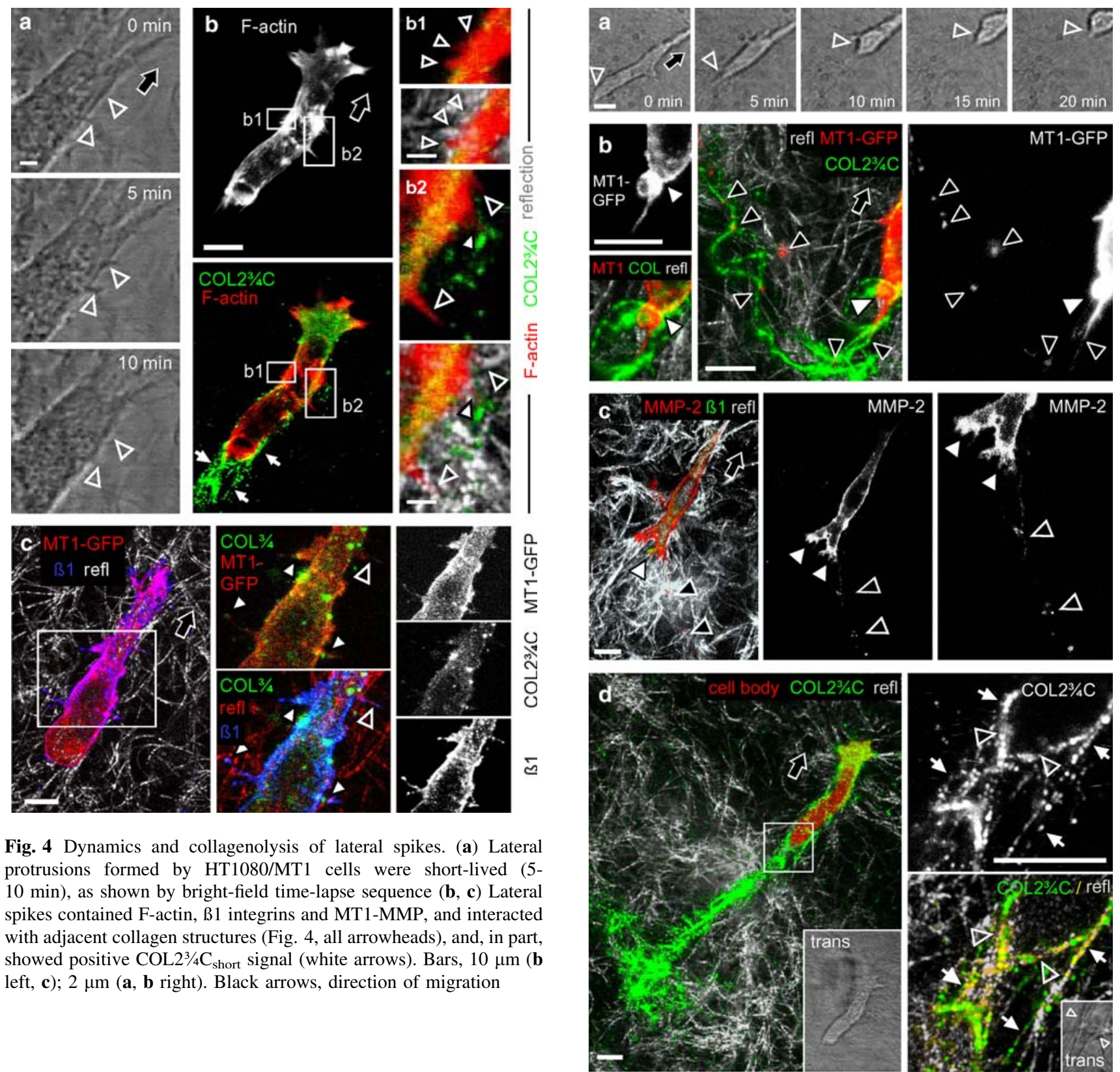

Fig. 5 Localization of proteases and proteolysis at the rear end. (a) Live-cell bright field microscopy of retracting rear in migrating HT1080/MT1 cell. Collagen lattices containing HT-1080/MT1-GFP (b) or HT-1080/MT1 cells $(\mathbf{c}, \mathbf{d})$ were fixed, stained with COL $23 / 4 \mathrm{C}_{\text {short }}$ Ab, MMP-2 Ab (AB 809, Chemicon) or B1 integrin Ab (clones 4B4 and K20, Coulter). MT1-GFP and MMP-2 were enriched at the trailing edge (white arrowheads) and deposited into the cell track (black arrowheads). Colocalization of MT1-GFP with collagenolytic path (b, middle, black arrowheads). (d) Proteolytic cell track of HT1080/MT1 cells after $10 \mathrm{~h}$ of migration within 3D collagen lattice. The proteolytic rear (empty arrowheads) was bordered by partially degraded fibers in parallel alignment (white arrowheads). All bars, $10 \mu \mathrm{m}$. Black arrows, direction of migration

fibrosarcoma, and breast cancer cells and represent potential tracks of least resistance and ongoing MMP activity via ECM-binding microparticles [9, 22, 48-50]. chymal cell migration within ECM, as shown for melanoma, 


\section{Conclusions}

In summary, different proteolytic structures contribute to pericellular tissue degradation and remodeling during invasive cell migration. First, leading pseudopodia segregate into an anterior proteolysis-free zone where traction force towards the ECM is generated, and an adjacent proteolytic zone at bifurcations and prior to the nucleus [9] (Fig. 6). Second, at such compression zones containing Factin, clustered integrins and surface proteases pericellular proteolysis towards belt-like collagen fibers is initiated [9]. Third, during forward movement sterically impeding fibers become cleaved and realigned in parallel, thereby supporting an increase in cell diameter. Protrusive spikes contribute to additional ECM degradation along the lateral edge of the cell. Fourth, proteolytically processed fibers become stably realigned and visible at the posterior cell edge where they border a tube-like matrix defect, i.e. a matrix track of altered composition and least resistance.

Whereas these steps of ECM remodelling form a continuous cycle that is embedded within the cell migration cycle, each protease-containing actin-rich structure is morphologically distinct and mediates a particular function. First, the tips of growing pseudopodia attach to the substrate, mediate integrin-dependent traction force, and bring the protease in close contact to the substrate thus targeting MMPs towards ECM substrate. Belt-like cell compressions by sterically impeding ECM structures cause

\section{1. belt-like compression}

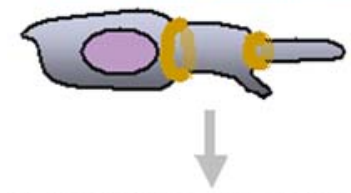

\section{2. belt-like cleavage}

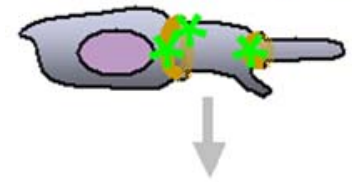

3. diameter increase

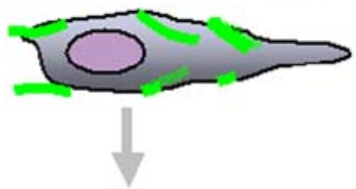

4. matrix defect generation

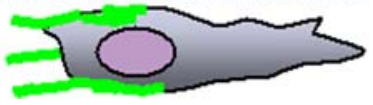

Fig. 6 Concept on dynamics of proteolytic belt-like ECM fibre removal by forward moving mesenchymal cell. For details, see main text locally confined cleavage, preferentially of those fibers that arrest pseudopod bifurcations or the nucleus. Thus, local pressure at regions of physical resistance against the cell body elicit surface protease activity by as yet unknown mechanisms. Next, lateral spikes and pseudopodia which do not contribute to pulling force generation push outward towards encountered scaffold structures, probe and focally degrade the ECM at their tips, and rapidly retract. Their function may include additional anchoring and stabilization of the cell body within the surrounding ECM and additional ECM processing. Although the proteolytic amount per spike is only minor, a sufficient spike frequency may substantially contribute to lateral ECM modification. Third, the trailing edge, in contrast to other proteolytic zones, is neither protrusive nor confronted with local pressure. Rather a relatively large, diffuse zone of protease distribution and ECM degradation is being formed, suggestive of constitutive and substantial ECM remodelling and ECM fragment generation. Track formation is therefore a consequence of the combined action of distinct proteolytic zones formed during cell migration allowing the cell to cleave and shape ECM fibers into a biochemically altered, parallel oriented cell track. The emerging path might be additionally modulated by ECM degradation fragments from laminin, fibronection or collagen that were shown to act chemotactically on neighbouring cells [51-53]. Microtrack-deposited proteases may cleave and thereby activate ECM-bound growth factors and chemokines produced by tumors or tumor-associated cells such as fibroblasts and macrophages and establish a chemotactic gradient $[54,55]$. All these structural and biochemical ECM alterations and new contents could attract tumor cells into an already established track and thereby mediate their conversion to multicellular invasion $[9,50]$.

Whereas these studies show the ECM remodelling during invasive cell migration in 3D model matrix, further work is needed to show proteolytic cell migration in vivo, i.e. the location and function of each proteolytic cell structure in the context of even more structural complex tissues. To visualize such proteolytic processes in vivo [22, 56], the development of protease-specific quenched substrates is required that not only freely reach the site of interest but, after cleavage, adopt a non-diffusive state with high temporal and spatial fidelity by, e.g. precipitation in situ. Together, high-resolution microscopy of cell invasion in vitro and in vivo will provide a detailed map of different proteolytic cell structures and their specific function in a tissue and organ context.

Acknowledgements We thank $M$. Ott for excellent technical assistance; S. Stack and Y. Wu as well as E. Deryugina and A.Y. Strongin for providing MDA-MB-231 and HT-1080 cell lines, respectively; D. Pei for supply of human MT1-MMP-GFP cDNA; and L. King (IBEX, Canada) for supply of COL2 $3 / 4 \mathrm{C}_{\text {short }}$ antibody. This 
work was supported by the Deutsche Forschungsgemeinschaft (FR 1155/7-1) and the Deutsche Krebshilfe (AZ 106950).

Open Access This article is distributed under the terms of the Creative Commons Attribution Noncommercial License which permits any noncommercial use, distribution, and reproduction in any medium, provided the original author(s) and source are credited.

\section{References}

1. Lauffenburger DA, Horwitz AF (1996) Cell migration: a physically integrated molecular process. Cell 84:359-369. doi:10.1016/ S0092-8674(00)81280-5

2. Kalluri R (2003) Basement membranes: structure, assembly and role in tumour angiogenesis. Nat Rev Cancer 3:422-433. doi: $10.1038 / \mathrm{nrc1094}$

3. Hotary K, Li XY, Allen E et al (2006) A cancer cell metalloprotease triad regulates the basement membrane transmigration program. Genes Dev 20:2673-2686. doi:10.1101/gad.1451806

4. Guise TA, Mohammad KS, Clines G et al (2006) Basic mechanisms responsible for osteolytic and osteoblastic bone metastases. Clin Cancer Res 12:6213-6216. doi:10.1158/1078-0432.CCR-06-1007

5. Gupta GP, Massague J (2006) Cancer metastasis: building a framework. Cell 127:679-695. doi:10.1016/j.cell.2006.11.001

6. Hanahan D, Weinberg RA (2000) The hallmarks of cancer. Cell 100:57-70. doi:10.1016/S0092-8674(00)81683-9

7. Sabeh F, Ota I, Holmbeck K et al (2004) Tumor cell traffic through the extracellular matrix is controlled by the membraneanchored collagenase MT1-MMP. J Cell Biol 167:769-781. doi: 10.1083/jcb.200408028

8. Adams JC (2001) Cell-matrix contact structures. Cell Mol Life Sci 58:371-392. doi:10.1007/PL00000864

9. Wolf K, Wu YI, Liu Y et al (2007) Multi-step pericellular proteolysis controls the transition from individual to collective cancer cell invasion. Nat Cell Biol 9:893-904. doi:10.1038/ncb1616

10. Condeelis J, Pollard JW (2006) Macrophages: obligate partners for tumor cell migration, invasion, and metastasis. Cell 124:263266. doi:10.1016/j.cell.2006.01.007

11. Weissleder R, Tung $\mathrm{CH}$, Mahmood U et al (1999) In vivo imaging of tumors with protease-activated near-infrared fluorescent probes. Nat Biotechnol 17:375-378. doi:10.1038/7933

12. Kircher MF, Weissleder R, Josephson L (2004) A dual fluorochrome probe for imaging proteases. Bioconjug Chem 15:242248. doi:10.1021/bc034151d

13. Artym VV, Zhang Y, Seillier-Moiseiwitsch F et al (2006) Dynamic interactions of cortactin and membrane type 1 matrix metalloproteinase at invadopodia: defining the stages of invadopodia formation and function. Cancer Res 66:3034-3043. doi: 10.1158/0008-5472.CAN-05-2177

14. Lehti K, Valtanen H, Wickstrom SA et al (2000) Regulation of membrane-type-1 matrix metalloproteinase activity by its cytoplasmic domain. J Biol Chem 275:15006-15013. doi:10.1074/ jbc.M910220199

15. Nabeshima K, Inoue T, Shimao Y et al (2000) Front-cell-specific expression of membrane-type 1 matrix metalloproteinase and gelatinase A during cohort migration of colon carcinoma cells induced by hepatocyte growth factor/scatter factor. Cancer Res 60:3364-3369

16. Mori H, Tomari T, Koshikawa N et al (2002) CD44 directs membrane-type 1 matrix metalloproteinase to lamellipodia by associating with its hemopexin-like domain. EMBO J 21:39493959. doi:10.1093/emboj/cdf411

17. Estreicher A, Muhlhauser J, Carpentier JL et al (1990) The receptor for urokinase type plasminogen activator polarizes expression of the protease to the leading edge of migrating monocytes and promotes degradation of enzyme inhibitor complexes. J Cell Biol 111:783-792. doi:10.1083/ jcb.111.2.783

18. Kjoller L, Hall A (2001) Rac mediates cytoskeletal rearrangements and increased cell motility induced by urokinase-type plasminogen activator receptor binding to vitronectin. J Cell Biol 152:1145-1157. doi:10.1083/jcb.152.6.1145

19. Artym VV, Kindzelskii AL, Chen WT et al (2002) Molecular proximity of seprase and the urokinase-type plasminogen activator receptor on malignant melanoma cell membranes: dependence on beta1 integrins and the cytoskeleton. Carcinogenesis 23:1593-1601. doi:10.1093/carcin/23.10.1593

20. Takino T, Saeki H, Miyamori H et al (2007) Inhibition of membranetype 1 matrix metalloproteinase at cell-matrix adhesions. Cancer Res 67:11621-11629. doi:10.1158/0008-5472.CAN-07-5251

21. Galvez BG, Matias-Roman S, Yanez-Mo M et al (2002) ECM regulates MT1-MMP localization with beta1 or alphavbeta3 integrins at distinct cell compartments modulating its internalization and activity on human endothelial cells. J Cell Biol 159:509-521. doi:10.1083/jcb.200205026

22. Wolf K, Mazo I, Leung H et al (2003) Compensation mechanism in tumor cell migration: mesenchymal-amoeboid transition after blocking of pericellular proteolysis. J Cell Biol 160:267-277. doi: 10.1083/jcb.200209006

23. Linder S (2007) The matrix corroded: podosomes and invadopodia in extracellular matrix degradation. Trends Cell Biol 17:107-117. doi:10.1016/j.tcb.2007.01.002

24. Mueller SC, Ghersi G, Akiyama SK et al (1999) A novel protease-docking function of integrin at invadopodia. J Biol Chem 274:24947-24952. doi:10.1074/jbc.274.35.24947

25. Yamaguchi H, Lorenz M, Kempiak S et al (2005) Molecular mechanisms of invadopodium formation: the role of the N-WASP-Arp2/3 complex pathway and cofilin. J Cell Biol 168:441-452. doi:10.1083/jcb.200407076

26. Weaver AM (2006) Invadopodia: specialized cell structures for cancer invasion. Clin Exp Metastasis 23:97-105. doi:10.1007/ s10585-006-9014-1

27. Saltel F, Destaing O, Bard F et al (2004) Apatite-mediated actin dynamics in resorbing osteoclasts. Mol Biol Cell 15:5231-5241. doi:10.1091/mbc.E04-06-0522

28. Cao J, Kozarekar P, Pavlaki M et al (2004) Distinct roles for the catalytic and hemopexin domains of membrane type 1-matrix metalloproteinase in substrate degradation and cell migration. J Biol Chem 279:14129-14139. doi:10.1074/jbc.M312120200

29. Takino T, Watanabe $\mathrm{Y}$, Matsui $\mathrm{M}$ et al (2006) Membrane-type 1 matrix metalloproteinase modulates focal adhesion stability and cell migration. Exp Cell Res 312:1381-1389. doi:10.1016/j.yexcr. 2006.01.008

30. Hartmann A, Boukamp P, Friedl P (2006) Confocal reflection imaging of 3D fibrin polymers. Blood Cells Mol Dis 36, 191-193. doi:10.1016/j.bcmd.2005.12.033

31. Miron-Mendoza M, Seemann J, Grinnell F (2008) Collagen Fibril Flow and Tissue Translocation Coupled to Fibroblast Migration in 3D Collagen Matrices. Mol Biol Cell 19(5):2051-2058

32. Sloane BF, Sameni M, Podgorski I et al (2006) Functional imaging of tumor proteolysis. Annu Rev Pharmacol Toxicol 46:301-315. doi:10.1146/annurev.pharmtox.45.120403.095853

33. Friedl P, Wolf K (2003) Tumour-cell invasion and migration: diversity and escape mechanisms. Nat Rev Cancer 3:362-374. doi:10.1038/nrc1075

34. Tam EM, Wu YI, Butler GS, et al (2002) Collagen binding properties of the membrane type-1 matrix metalloproteinase (MT1-MMP) hemopexin C domain. The ectodomain of the 44$\mathrm{kDa}$ autocatalytic product of MT1-MMP inhibits cell invasion by disrupting native type I collagen cleavage. J Biol Chem 277:39005-39014. doi:10.1074/jbc.M206874200 
35. Hotary KB, Allen ED, Brooks PC et al (2003) Membrane type I matrix metalloproteinase usurps tumor growth control imposed by the three-dimensional extracellular matrix. Cell 114:33-45. doi:10.1016/S0092-8674(03)00513-0

36. Hotary K, Allen E, Punturieri A et al (2000) Regulation of cell invasion and morphogenesis in a three-dimensional type I collagen matrix by membrane-type matrix metalloproteinases 1,2 , and 3. J Cell Biol 149:1309-1323. doi:10.1083/jcb.149.6.1309

37. Nakahara H, Howard L, Thompson EW et al (1997) Transmembrane/cytoplasmic domain-mediated membrane type 1matrix metalloprotease docking to invadopodia is required for cell invasion. Proc Natl Acad Sci USA 94:7959-7964. doi: 10.1073/pnas.94.15.7959

38. Dahl KN, Engler AJ, Pajerowski JD et al (2005) Power-law rheology of isolated nuclei with deformation mapping of nuclear substructures. Biophys J 89:2855-2864. doi:10.1529/biophysj.105.062554

39. Yamauchi K, Yang M, Jiang P et al (2005) Real-time in vivo dual-color imaging of intracapillary cancer cell and nucleus deformation and migration. Cancer Res 65:4246-4252. doi: 10.1158/0008-5472.CAN-05-0069

40. Cukierman E, Pankov R, Stevens DR et al (2001) Taking cellmatrix adhesions to the third dimension. Science 294:1708-1712. doi:10.1126/science.1064829

41. Wolf K, Friedl P (2005) Functional imaging of pericellular proteolysis in cancer cell invasion. Biochimie 87:315-320. doi: 10.1016/j.biochi.2004.10.016

42. Taylor AC, Robbins E (1963) Observations on microextensions from the surface of isolated vertebrate cells. Dev Biol 7:660-673. doi:10.1016/0012-1606(63)90150-7

43. Buccione R, Orth JD, McNiven MA (2004) Foot and mouth: podosomes, invadopodia and circular dorsal ruffles. Nat Rev Mol Cell Biol 5:647-657. doi:10.1038/nrm1436

44. Yamaguchi H, Wyckoff J, Condeelis J (2005) Cell migration in tumors. Curr Opin Cell Biol 17:559-564. doi:10.1016/j.ceb.2005. 08.002

45. Pfaff M, Du X, Ginsberg MH (1999) Calpain cleavage of integrin beta cytoplasmic domains. FEBS Lett 460:17-22. doi:10.1016/ S0014-5793(99)01250-8

46. Carragher NO, Levkau B, Ross R et al (1999) Degraded collagen fragments promote rapid disassembly of smooth muscle focal adhesions that correlates with cleavage of pp125(FAK), paxillin, and talin. J Cell Biol 147:619-630. doi:10.1083/jcb.147.3.619

47. Franco SJ, Huttenlocher A (2005) Regulating cell migration: calpains make the cut. J Cell Sci 118:3829-3838. doi:10.1242/ jcs.02562

48. Friedl P, Maaser K, Klein CE et al (1997) Migration of highly aggressive MV3 melanoma cells in 3-dimensional collagen lattices results in local matrix reorganization and shedding of alpha2 and beta1 integrins and CD44. Cancer Res 57:2061-2070

49. Mayer C, Maaser K, Daryab N et al (2004) Release of cell fragments by invading melanoma cells. Eur J Cell Biol 83:709715. doi:10.1078/0171-9335-00394

50. Gaggioli C, Hooper S, Hidalgo-Carcedo C et al (2007) Fibroblast-led collective invasion of carcinoma cells with differing roles for RhoGTPases in leading and following cells. Nat Cell Biol 9:1392-1400. doi:10.1038/ncb1658

51. Giannelli G, Falk-Marzillier J, Schiraldi O et al (1997) Induction of cell migration by matrix metalloprotease-2 cleavage of laminin-5. Science 277:225-228. doi:10.1126/science.277.5323.225

52. Clark RA, Wikner NE, Doherty DE et al (1988) Cryptic chemotactic activity of fibronectin for human monocytes resides in the 120-kDa fibroblastic cell-binding fragment. J Biol Chem 263:12115-12123
53. Nabeshima K, Kataoka H, Koono M (1986) Enhanced migration of tumor cells in response to collagen degradation products and tumor cell collagenolytic activity. Invasion Metastasis 6:270-286

54. Mueller MM, Fusenig NE (2004) Friends or foes-bipolar effects of the tumour stroma in cancer. Nat Rev Cancer 4:839-849. doi: $10.1038 /$ nrc 1477

55. Egeblad M, Werb Z (2002) New functions for the matrix metalloproteinases in cancer progression. Nat Rev Cancer 2:161174. doi: $10.1038 / \mathrm{nrc} 745$

56. Friedl P, Wolf K, Harms G et al (2007) Biological second and third harmonic generation microscopy. Curr Protoc Cell Biol Chapter 4: Unit 415

57. Bowden ET, Onikoyi E, Slack R et al (2006) Co-localization of cortactin and phosphotyrosine identifies active invadopodia in human breast cancer cells. Exp Cell Res 312:1240-1253. doi: 10.1016/j.yexcr.2005.12.012

58. Billinghurst RC, Dahlberg L, Ionescu M et al (1997) Enhanced cleavage of type II collagen by collagenases in osteoarthritic articular cartilage. J Clin Invest 99:1534-1545. doi:10.1172/JCI119316

59. Barbolina MV, Stack MS (2008) Membrane type 1-matrix metalloproteinase: Substrate diversity in pericellular proteolysis. Semin Cell Dev Biol 19:24-33. doi:10.1016/j.semcdb.2007.06.008

60. d'Ortho MP, Stanton H, Butler M et al (1998) MT1-MMP on the cell surface causes focal degradation of gelatin films. FEBS Lett 421:159-164. doi:10.1016/S0014-5793(97)01555-X

61. Bravo-Cordero JJ, Marrero-Diaz R, Megias D et al (2007) MT1MMP proinvasive activity is regulated by a novel Rab8-dependent exocytic pathway. EMBO J 26:1499-1510. doi:10.1038/ sj.emboj.7601606

62. Demou ZN, Awad M, McKee T et al (2005) Lack of telopeptides in fibrillar collagen I promotes the invasion of a metastatic breast tumor cell line. Cancer Res 65:5674-5682. doi:10.1158/0008-5472. CAN-04-1682

63. Sahai E, Marshall CJ (2003) Differing modes of tumour cell invasion have distinct requirements for Rho/ROCK signalling and extracellular proteolysis. Nat Cell Biol 5:711-719. doi: 10.1038/ncb1019

64. Kindzelskii AL, Amhad I, Keller D et al (2004) Pericellular proteolysis by leukocytes and tumor cells on substrates: focal activation and the role of urokinase-type plasminogen activator. Histochem Cell Biol 121:299-310. doi:10.1007/s00418-004-0639-3

65. Mook OR, Van Overbeek C, Ackema EG et al (2003) In situ localization of gelatinolytic activity in the extracellular matrix of metastases of colon cancer in rat liver using quenched fluorogenic DQ-gelatin. J Histochem Cytochem 51:821-829

66. Kurschat $P$, Wickenhauser C, Groth W et al (2002) Identification of activated matrix metalloproteinase-2 (MMP-2) as the main gelatinolytic enzyme in malignant melanoma by in situ zymography. J Pathol 197:179-187. doi:10.1002/path.1080

67. Sukhova GK, Schonbeck U, Rabkin E et al (1999) Evidence for increased collagenolysis by interstitial collagenases- 1 and -3 in vulnerable human atheromatous plaques. Circulation 99:25032509

68. Hollander AP, Pidoux I, Reiner A et al (1995) Damage to type II collagen in aging and osteoarthritis starts at the articular surface, originates around chondrocytes, and extends into the cartilage with progressive degeneration. J Clin Invest 96:2859-2869. doi: 10.1172/JCI118357

69. Xu J, Rodriguez D, Petitclerc E et al (2001) Proteolytic exposure of a cryptic site within collagen type IV is required for angiogenesis and tumor growth in vivo. J Cell Biol 154:1069-1079. doi:10.1083/jcb.200103111 